\title{
Walter-Trummert-Preis Chefredakteur bei Springer Medizin ausgezeichnet
}

Dr. Dirk Einecke prägt den Medizinjournalismus seit über einem Vierteljahrhundert. Nun bekam er von der Vereinigung der Deutschen Medizinischen Fach- und Standespresse e. V. für seine Leistungen mit dem WalterTrummert-Preis ausgezeichnet. Der mit 2.000 Euro dotierte Preis wird seit 1974 zweckge-

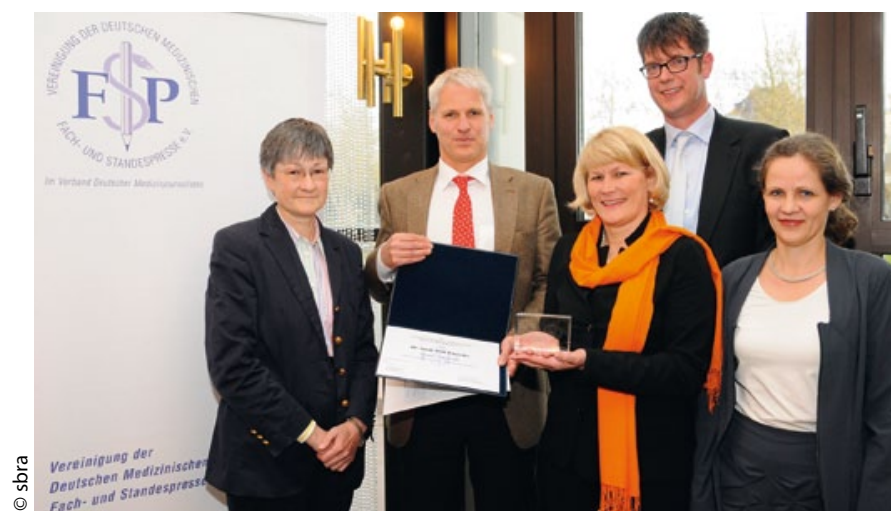

bunden für besondere Verdienste in der Medizinpublizistik verliehen.

Einecke ist Chefredakteur und Herausgeber bei Springer Medizin und "mit Herz und Seele Medizinjournalist, allein 2011 hat er 284 Beiträge geschrieben", sagte Harm van Maanen, Executive Vice President von Springer

Verleihung des Walter-TrummertPreises. Von links: Dr. Susanne Heinzl, Dr. Dirk Einecke, Dr. Julia Rautenstrauch, Harm van Maanen, Dr. Wiebke Kathmann, wie Heinzl und Rautenstrauch im Vorstand des VMWJ.
Medizin, in seiner Laudatio. Seine Liebe zum Schreiben hat Einecke während seines Medizinstudiums entdeckt, er fuhr von Termin zu Termin und verdiente sein erstes Zeilengeld. Und er blieb dabei: Nach seiner Approbation ging er zur Medical Tribune, 1996 zur Münchner Medizinischen Wochenschrift (MMW), deren Chefredakteur er 1998 wurde;

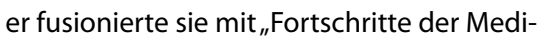
zin" und gründete neue Titel wie InfoDiabetologie oder CardioVasc.

Stets habe er es verstanden, seine Liebe für die medizinischen Inhalte neben seinen Managementaufgaben nicht zu vernachlässigen, sagte van Maanen. Einecke kenne sich in der Medizin gut aus und sei in der Lage, jeden Beitrag von der ersten bis zur letzten Zeile lesenswert zu gestalten. Er lade den Leser förmlich ein, sich in den Artikel einzuarbeiten: „Einecke hat die Tinte nicht im Blut, sein Blut ist Tinte!".

Angela Speth 